ISSN 0103-9954

\title{
ANÁLISE QUALITATIVA DA ARBORIZAÇÃO DE RUAS DO CONJUNTO HABITACIONAL TANCREDO NEVES, SANTA MARIA - RS
}

\section{QUALITATIVE EVALUATION OF THE URBAN VEGETATION IN TANCREDO NEVES HABITATIONAL CONJUNCT, SANTA MARIA, RIO GRANDE DO SUL STATE}

\author{
Italo Filippi Teixeira ${ }^{1}$
}

\section{RESUMO}

No Conjunto Habitacional Tancredo Neves, Santa Maria-RS, foi realizado um censo da arborização de suas ruas e avenida, permitindo, desse modo, avaliar qualitativamente a vegetação que a compõe. Das 112 espécies vegetais que totalizam 2.788 indivíduos distribuidos irregularmente, 14 espécies perfazem 70,6\% do total. A maioria possui porte jovem, ou apresenta-se em estágio de muda, com sistema radicular profundo sem causar danos, condição fitossanitária satisfatória e a área livre predominante é restrita. A necessidade de tratamento com maior freqüência é a poda leve $(43,3 \%)$. Grande parte dos danos são provocados por poda $(46,0 \%)$ executados pelos próprios moradores. Os vegetais são compatíveis em sua maioria $(44,9 \%)$ em relação aos equipamentos públicos e edificações.

Palavras-chave: Arborização, vegetação urbana, paisagismo.

\begin{abstract}
Tancredo Neves area, Santa Maria, RS, a census was conducted with the objective of investigating the urban vegetation of its streets and avenues thus allowing the qualitative evaluation of its vegetation components. From 112 vegetal species, which account for 2,778 units distributed irregularly, 14 species totalized 70, 6 of the total. Most of them have a new dimension, are in the seedling, stage and are not under any spinning. The prevailing area is limited, with a deep radicular system without causing any damage, and a satisfactory phyto-sanitary condition. The patterns regarding its distance from the curb and buildings and walls are in accordance with the literature. Only the distance from the lampposts is not accordance with these principles. The most frequent treatment needed consists of pruning the tree lightly (43,3\%). Most of the damages were caused by pruning $(46,0 \%)$ which is done by local inhabitants. The vegetables are compatible, in their great majority $(44,9 \%)$ to the equipments and buildings.
\end{abstract}

Key words: arboreus, urban vegetation, landscape.

1. Engenheiro Florestal, Mestrando pelo Programa de Pós-Graduação em Engenharia Florestal, Centro de Ciências Rurais, Universidade Federal de Santa Maria, CEP: 97105-900, Santa Maria. (RS). 


\section{INTRODUÇÃO}

A ação do ser humano junto ao meio ambiente, historicamente, sempre foi limitada em função do próprio espaço que ocupava. Porém, com o advento da Revolução Industrial, esta relação é totalmente alterada e as mudanças de natureza antrópica geram um desequilíbrio tanto mais acentuado quanto é o crescimento populacional e das cidades.

Dentro das urbes, a falta de planejamento gera padrões ambientais aquém dos recomendáveis para uma vida salutar. O processo desenfreado de ocupação do solo e uma política imobiliária extremamente agressiva determinaram a restrição dos ambientes que oportunizassem o contato do homem urbano com o "verde". Pequenas áreas, com vegetação exótica e mobiliário nem sempre compatível com as exigências do público foi o que restou no ambiente urbano.

Uma simples análise dessas cidades, determina uma necessidade premente quanto ao uso da vegetação, objetivando o enriquecimento da paisagem e da qualidade do meio ambiente. Essa vegetação traduzida na forma de arborização de ruas, atua como um dos fatores dotados de maior capacidade integrativa das realizações humanas, corporificados por meio das construções, no meio ambiente. Porém, os modelos observados em vários municípios, inclusive Santa Maria-RS, repetemse em relação à distribuição e composição das espécies vegetais nas vias públicas.

Com raras exceções, as manifestações no intuito de realizar arborização de ruas sempre se caracterizaram por ser um evento casual e, eminentemente, sem o mínimo respaldo técnicocientífico.

Qualquer intervenção técnica na arborização, em Santa Maria-RS, deverá oportunizar um prévio e aprofundado estudo da situação atual e, a partir daí tecer análises para seu replanejamento e sua reestruturação.

Isso posto, o trabalho tem como objetivo a análise qualitativa dos exemplares vegetais que formam a arborização das ruas do Conjunto Habitacional Tancredo Neves, Santa Maria-RS.

\section{REVISÃO BIBLIOGRÁFICA}

As cidades representam os pontos mais significativos de mudança de natureza física pela ação antrópica, apresentando uma paisagem natural modificada pela dinamicidade antropogenética ligada aos sistemas políticos e econômicos dominantes, ao longo do processo histórico. As mudanças do meio físico que ocorrem nas áreas urbanizadas, constituem um dos marcos de ação do homem sobre a natureza (MERCANTE, 1991).

A cidade imprime modificações nos parâmetros de superfície e da atmosfera que por sua vez, conduz a uma alteração no balanço de energia. Cada vez, torna-se evidente a capacidade do homem em criar microclimas e alterar substancialmente o clima sobre as áreas urbanas. As árvores e outros vegetais, interceptando, absorvendo, refletindo e transmitindo radiação solar, captando e transpirando água e interferindo com a direção e velocidade dos ventos podem ser extremamente eficientes na melhoria do clima urbano (LOMBARDO, 1990).

Atualmente existe uma tendência cada vez mais freqüente de se analisar as cidades como sistemas integrados, vivos onde os diferentes componentes interagem com o bom funcionamento do

Ciência Florestal, v. 9, n. 2, 1999 
todo, dependendo da eficiência de cada uma das partes. Dessa forma cada componente tem que ser avaliado isoladamente e analisado dentro do sistema integral a fim de que se possa identificar e localizar precisamente os problemas, suas causas e, principalmente, encontrar soluções que garantam ao homem urbano as condições mínimas para uma vida saudável.

Sem dúvida, as cidades não são todas iguais. Entretanto, geralmente possuem vários, senão todos os elementos e características em comum: sistema viário (estruturado ou não); espaços residenciais; espaços comerciais e de serviço; espaços industriais; espaços institucionais; espaços livres ou abertos. E a julgar tanto pela forma universalizante do tratamento das questões urbanas quanto pelas normas gerais que regem a urbanização no Brasil, a começar pelos códigos de postura municipais e leis de loteamentos, é de considerar-se que as cidades, em todos lugares, sejam mesmo muito parecidas (MILANO, 1992).

Ao contrário dos ambientes naturais, ecologicamente equilibrados em termos climáticos, hidrológicos e do balanço energético, as cidades apresentam artificialidades como impermeabilização do solo, materiais altamente refletores, absorventes e transmissores de energia, poluição (atmosférica, hídrica, edáfica, sonora e visual) e reduzida cobertura vegetal. Tais características afetam negativamente o ambiente e a paisagem urbana e portanto interferem negativamente na qualidade de vida humana. Pode-se a partir desse tipo de análise, enquadrar as cidades na categoria de ecossistemas e o seu funcionamento ser estudado do ponto de vista ecológico (CESTARO, 1985).

Em termos de benefícios gerais, a vegetação urbana contribui para a estabilidade microclimática, para a melhoria da qualidade do ar, para a redução da poluição sonora, visual e, conseqüentemente, para a melhoria da saúde física e mental da população (BERNATZKY, 1978; GREY \& DENEKE, 1978; HEISLER, 1974; SCHUBERT, 1979; LAPOIX, 1979).

Em um sentido amplo, GREY \& DENEKE (1978) definem arborização urbana como o conjunto de terras públicas e particulares com cobertura arbórea que uma cidade apresenta.

Segundo BALMER \& ZAMBRANA (1977); MIRANDA (1970), SCHUBERT (1979), SOUZA (1973) e WYMAN (1972), qualitativamente a arborização de ruas será tanto melhor quanto mais detalhadamente forem considerados os fatores de planejamento, quais sejam:

a) Seleção de espécies/variedades em termos de adaptabilidade, ecologia, fitossanidade, características morfológicas e fisiológicas;

b) condições locais em termos de espaço disponível para plantio, tipo de tráfego e poluição, fiação aérea e outros;

c) sobre o plantio em si, destaca-se a composição percentual por espécie, qualidade das mudas, espaçamentos e compatibilização paisagística;

d) manutenção, incluindo reposição, tutoramento, poda, controle fitossanitário, irrigação e adubação.

Desses aspectos, destacam-se, para uma maior ou melhor qualidade da arborização de ruas, a composição percentual das espécies utilizadas (equilibrada) e a compatibilização entre o porte das árvores e o espaço físico disponível para o plantio, nem sempre adequadamente considerados.

O processo de avaliação da arborização, tanto qualitativo como quantitativo depende, assim, da realização de inventários que, em função de objetivos especialmente definidos, serão 
fundamentados em diferentes metodologias e poderão apresentar diferentes graus de precisão (MILANO, 1992).

\section{MATERIAIS E MÉTODOS}

Distando, aproximadamente, $8 \mathrm{~km}$ do centro de Santa Maria - RS, o Conjunto Habitacional Tancredo Neves situa-se na região oeste, possuindo uma população de 11.035 habitantes, segundo o Censo de 1991, com a projeção de 15.000 para 1996. Esse Bairro, possuindo uma área total de 115ha, foi entregue à população no segundo semestre de 1986 para habitarem as 3.184 moradias que ocupam uma área de 59 ha, sendo o lote mínimo de $200 \mathrm{~m}^{2}$, todos possuindo recuo que varia de 4 $\mathrm{m}$ até $6 \mathrm{~m}$. O sistema viário é padronizado para todas as ruas e avenida, sendo a largura de $8 \mathrm{~m}$ e 9,5 $\mathrm{m}$, cada pista, respectivamente e as calçadas com $3 \mathrm{~m}$ de largura.

A escolha do local deu-se em virtude da estrutura homogênea do Conjunto, permitindo, assim, a reconstituição da arborização atual mediante ação dos órgãos competentes. Buscando materializar os objetivos desse trabalho e considerando que a análise da arborização de ruas de uma cidade só é possível com conhecimento da sua situação real, foi realizado um censo nas 55 vias públicas do Conjunto Habitacional Tancredo Neves. Ele se baseou em um formulário estruturado segundo SANTOS \& TEIXEIRA (1990) e MILANO (1992) em que foram registradas as seguintes informações:

a) Rua: nome da rua de acordo com o mapa oficial da cidade;

b) lado da rua - segundo numeração das residências;

c) espécie - nome comum da espécie;

d) origem - se a espécie é de origem exótica, introduzida de países estrangeiros, ou nativa da região ou mesmo do Brasil;

e) porte - referente à altura do vegetal analisado:

e.1) muda - vegetal com até $1 \mathrm{~m}$ de altura;

e.2) jovem - vegetal com altura entre $1,01 \mathrm{~m}$ e $3 \mathrm{~m}$;

e.3) adulta - vegetal com altura superior a $3 \mathrm{~m}$ ou porte adulto de acordo com literatura específica a cada espécie;

f) área livre - considerada a área desprovida de pavimentação e reservada ao plantio da vegetação;

f.1.) ampla - área livre igual ou superior a $1 \mathrm{~m}^{2}$;

f.2.) regular - área livre igual a $0,5 \mathrm{~m}^{2}$;

f.3.) restrita - área livre inferior a $0,5 \mathrm{~m}^{2}$;

f.4.) inexistente - quando a área pavimentada encobre todo o colo da planta;

g) sistema radicular - classificou-se quanto às seguintes situações:

g.1) profundo sem danos - o sistema radicular apresenta-se profundo sem danos à calçada, muros, pavimentação ou meio fio;

g.2.) profundo com danos - o sistema radicular apresenta-se profundo, porém ocorrem danos que pode ser tanto nas calçadas, muros, pavimentação ou meio fio e até em ambos;

g.3.) superficial sem danos - o sistema radicular apresenta-se superficial, porém, até o momento não se observa alterações em calçadas, muros, pavimentação ou meio fio provocadas por ele;

Ciência Florestal, v. 9, n. 2, 1999 
g.4.) superficial com danos - o sistema radicular apresenta-se superficial, observando-se alterações em calçadas, muros, pavimentação ou meio-fio provocadas por ele;

h) condição física e sanitária - considerou-se:

h.1. boa - isenta de sinais de pragas, doenças ou injúrias mecânicas. Apresenta forma característica da espécie;

h.2. satisfatória - apresenta pequenos problemas de pragas, doenças ou danos físicos. Necessita de poda corretiva;

h.3. ruim - apresenta severos danos de pragas, doenças ou danos físicos. Requer muito trabalho para recuperação;

h.4. morta - ou que apresenta morte eminente;

i) necessidade de tratamento:

i.1.controle fitossanitário - controle de pragas ou doenças que estejam manifestas na vegetação;

i.2.poda leve - retirada de ramos secos, doentes ou malformados, sem alterar a estrutura típica da espécie;

i.3.poda pesada - retirada de grande quantidade de ramificação alterando a estrutura típica da espécie;

i.4.reparo de danos físicos - reparo de danos causados ao vegetal por ações diversas intencionais ou não;

i.5.remoção com reposição - remoção do vegetal com o replantio da mesma espécie ou outra compatível;

i.6.remoção sem-reposição - remoção do vegetal sem reposição de outras espécies;

i.7.nenhum - quando o vegetal não apresenta, no momento do censo, nenhuma necessidade de tratamento;

j) danos físicos causados ao vegetal:

j.1.vandalismo - ação depredatória por transeuntes ou mesmo moradores;

j.2.acidente - situação gerada por danos não-intencionais;

j.3.poda - ação realizada sem-procedimento técnico;

j.4.tutoramento - mediante o amarrio unindo o tutor à vegetação ou mesmo apenas a presença física muito próxima ao caule da vegetação gerando danos pelo atrito;

j.5.obras de construção - dano gerado pelas construções prediais ou de estruturas de apoio para a moradia;

j.6.nenhum - quando o vegetal não apresenta nenhum dano físico em sua estrutura;

1) compatibilização - relação do vegetal com o espaço tridimensional onde está localizado em relação a estruturas como muros, fiação elétrica, postes diversos, construções e outras formas de vegetação: 1.1.compatível - quando o espaço que o comporta permite o seu desenvolvimento sem-necessidade de intervenção mecânica;

1.2.medianamente compatível - requer poda leve, porém sistemática para controle do tamanho e forma da copa;

1.3. pouco compatível - requer poda pesada e sistemática para controle do tamanho e forma da copa;

1.4.incompatível - quando o desenvolvimento do vegetal está comprometido em função de estruturas como muros, fiação elétrica, postes diversos, construções e outras formas de vegetação e sua permanência poderá incorrer em um desenvolvimento inadequado ou até mesmo em riscos para essas estruturas e para a população em geral. 


\section{RESULTADOS E DISCUSSÃO}

O censo da arborização de ruas do Conjunto Habitacional Tancredo Neves indicou a existência de 2.788 exemplares, distribuídos em 112 espécies vegetais (Tabela 1 ).

TABELA 1: Nome comum, nome botânico, freqüência absoluta e relativa.

\begin{tabular}{|c|c|c|c|}
\hline Nome comum & Nome botânico & Frequiência & Freqüência \\
\hline Cinamomo & Melia azedarach & 504 & 18,07 \\
\hline Ligustro & Ligustrum lucidum & 324 & 11,62 \\
\hline Extremosa & Lagestroemia indica & 232 & 8,32 \\
\hline Laranjeira & Citrus sinensis & 164 & 5,9 \\
\hline Chuva-de-ouro & Senna multijuga & 128 & 4,60 \\
\hline Ipê-amarelo & Tabebuia chrysotricha & 116 & 4,16 \\
\hline Sangüínea & Euphorbia cotinifolia & 85 & 3,05 \\
\hline Mimo-de-Vênus & Hibiscus rosa-sinensis & 82 & 2,94 \\
\hline Tipuana & Tipuana tipu & 75 & 2,70 \\
\hline Goiabeira & Psidium guajava & 61 & 2,22 \\
\hline Grevilea-robusta & Grevilea robusta & 55 & 2,00 \\
\hline Jambolão & Eugenia jambolana & 52 & 1,86 \\
\hline Limoeiro & Citrus limon & 44 & 1,60 \\
\hline Sibipiruna & Caesalpinia peltophoroides & 44 & 1,60 \\
\hline Espirradeira & Nerium oleander & 39 & 1,40 \\
\hline Salso-chorão & Salix babylonica & 39 & 1,40 \\
\hline Canafístula & Pelthophorum dubium & 37 & 1,32 \\
\hline Mangueira & Mangifera indica & 34 & 1,21 \\
\hline Amoreira & Morus nigra & 33 & 1,18 \\
\hline Siriaco & Hibiscus syriacus & 30 & 1,07 \\
\hline Jacarandá & Jacaranda mimosifolia & 29 & 1,04 \\
\hline Cipreste & Cupressus sp & 28 & 1,00 \\
\hline Sesbania & Sesbania virgata & 28 & 1,00 \\
\hline Abacateiro & Persea americana & 27 & 0,96 \\
\hline Ingá & Inga marginata & 24 & 0,86 \\
\hline
\end{tabular}

Continua... 
TABELA 1: Continuação ...

\begin{tabular}{|c|c|c|c|}
\hline Nome comum & Nome botânico & Freqüência & Freqüência \\
\hline Angiquinho & Calliandra selloi & 24 & 0,86 \\
\hline Álamo & Populus deltoides & 23 & 0,82 \\
\hline Ipê-roxo & Tabebuia avellanedae & 23 & 0,82 \\
\hline Nespereira & Eryobotrya japonica & 22 & 0,80 \\
\hline Pessegueiro & Prunus persica & 19 & 0,70 \\
\hline Uva-do-Japão & Hovenia dulcis & 19 & 0,70 \\
\hline Pinus & Pinus elliottii & 18 & 0,64 \\
\hline Bergamoteira & Citrus reticulata & 17 & 0.61 \\
\hline Grevilea-anã & Grevilea banksii & 17 & 0.61 \\
\hline Manduirana & Senna macranthera & 17 & 0.61 \\
\hline Angico-vermelho & Parapiptadenia rigida & 13 & 0.46 \\
\hline Guajuvira & Patagonula americana & 13 & 0.46 \\
\hline Gerivá & Syagrus romanzoffiana & 12 & 0.43 \\
\hline Guapuruvú & Schizolobium parahyba & 12 & 0.43 \\
\hline Acácia-imperal & Cassia fistula & 10 & 0.35 \\
\hline Roseira & Rosa spp & 10 & 0.35 \\
\hline Azaléia & Rhododendro indicum & 8 & 0.29 \\
\hline Canela & Nectandra sp & 8 & 0.29 \\
\hline Pitanga & Eugenia uniflora & 8 & 0.29 \\
\hline Carobinha-louca & Tecoma stans & 7 & 0.25 \\
\hline Cedro & Cedrela fissilis & 6 & 0.21 \\
\hline Orelha-de-urso & Tibouchina holosericea & 6 & 0.21 \\
\hline Plátano & Platanus occidentalis & 6 & 0.21 \\
\hline Salso-nativo & Salix humboldtiana & 6 & 0.21 \\
\hline Acácia-mimosa & Acacia podalyriaefolia & 5 & 0.18 \\
\hline Camélia & Camellia japonica & 5 & 0.18 \\
\hline Corticeira-do-banhado & Erythrina cristagalli & 5 & 0.18 \\
\hline Iuca & Yuca aloypholia & 5 & 0.18 \\
\hline Paineira & Chorisia speciosa & 5 & 0.18 \\
\hline Primavera & Brunfelsia uniflora & 5 & 0.18 \\
\hline N.I. & & 5 & 0.18 \\
\hline Araçá & Psidium cattleianum & 4 & 0.14 \\
\hline Aroeira-piriquita & Schinus molle & 4 & 0.14 \\
\hline
\end{tabular}


TABELA 1: Continuação ...

\begin{tabular}{|c|c|c|c|}
\hline Nome comum & Nome botânico & Freqüência & Frequiência \\
\hline Calistemon & Callistemon speciosus & 4 & 0.14 \\
\hline Canforeira & Cinnamomum camphora & 4 & 0.14 \\
\hline Figueira & Ficus enormis & 4 & 0.14 \\
\hline Girassol & Helianthus annuus & 4 & 0.14 \\
\hline Pata-de-vaca & Bauhinia candicans & 4 & 0.14 \\
\hline Acacia-negra & Acacia mearnsii & 3 & 0.11 \\
\hline Canudo-de-apito & Senna corymbosa & 3 & 0.11 \\
\hline Erva-mate & Ilex paraguariensis & 3 & 0.11 \\
\hline Falsa-seringueira & Ficus elastica & 3 & 0.11 \\
\hline Fedegoso & Cassia alata & 3 & 0.11 \\
\hline Grinalda-de-noiva & Spiraea ariifolia & 3 & 0.11 \\
\hline Guabiju & Myrcianthes pungens & 3 & 0.11 \\
\hline Jasmim & Gardenia jasminoides & 3 & 0.11 \\
\hline Abutilon & Abutilon striatum & 2 & 0.071 \\
\hline Açoita-cavalo & Luehea divaricata & 2 & 0.071 \\
\hline Alamanda-arbustiva & Alamanda neriifolia & 2 & 0.071 \\
\hline Aroeira-vermelha & Schinus terebenthifolius & 2 & 0.071 \\
\hline Bananeira & Musa acuminata & 2 & 0.071 \\
\hline Bico-de-papagaio & Euphorbia pulcherrima & 2 & 0.071 \\
\hline Braquiquito & Brachychyton populneus & 2 & 0.071 \\
\hline Butiá & Butia eriospatha & 2 & 0.071 \\
\hline Camboatá-branco & Matayba elaeaguinoides & 2 & 0.071 \\
\hline Caroba & Jacaranda micrantha & 2 & 0.071 \\
\hline Dama-da-noite & Cestrum nocturnum & 2 & 0.071 \\
\hline Excelsa & Araucaria excelsa & 2 & 0.071 \\
\hline Falso-barbatimão & Cassia leptophylla & 2 & 0.071 \\
\hline Figueira & Ficus macrocarpa & 2 & 0.071 \\
\hline Flamboyant & Delonix regia & 2 & 0.071 \\
\hline Jasmim-manga & Plumeria acutifolia & 2 & 0.071 \\
\hline Pereira & Pyrus communis & 2 & 0.071 \\
\hline Pinheiro-brasileiro & Araucaria angustifolia & 2 & 0.071 \\
\hline Romanzeiro & Punica granatum & 2 & 0.071 \\
\hline Timbaúva & Enterolobium contortisiliquum & 2 & 0.071 \\
\hline
\end{tabular}


TABELA 1: Continuação ...

\begin{tabular}{|c|c|c|c|}
\hline Nome comum & Nome botânico & Freqüência & Freqüência \\
\hline Unha-de-gato & Acacia bonariensis & 2 & 0.071 \\
\hline Acalifa & Acalypha tricolor & 1 & 0.035 \\
\hline Acer & Acer negundo & 1 & 0.035 \\
\hline Araticum & Rollinia rugulosa & 1 & 0.035 \\
\hline Mil-cores & Breynia nivosa & 1 & 0.035 \\
\hline Camboatá-vermelho & Cupania vernalis & 1 & 0.035 \\
\hline Canjerana & Cabralea canjerana & 1 & 0.035 \\
\hline Carvalinho & Casearia sylvestris & 1 & 0.035 \\
\hline Figueira & Ficus benjamina & 1 & 0.035 \\
\hline Guabiroba & C. xanthocarpa & 1 & 0.035 \\
\hline Ipê-da-serra & Tabebuia alba & 1 & 0.035 \\
\hline Limeira & Citrus aurantifolia & 1 & 0.035 \\
\hline Magnólia & Magnolia grandiflora & 1 & 0.035 \\
\hline Pau-brasil & Caesalpinia echinata & 1 & 0.035 \\
\hline Pau-ferro & Caesalpinia ferrea & 1 & 0.035 \\
\hline Quiri & Paulownia tomentosa & 1 & 0.035 \\
\hline Seafórtia & Arcontophoenix & 1 & 0.035 \\
\hline Trichilia & Trichilia elegans & 1 & 0.035 \\
\hline Pinheiro-japonês & Cryptomeria japonica & 1 & 0.035 \\
\hline Vergonha-de-estudante & Dombeya wallichi & 1 & 0.035 \\
\hline TOTAL & & 2.788 & 100 \\
\hline
\end{tabular}

O número total de indivíduos apresenta uma distribuição totalmente irregular, sendo que apenas 14 espécies perfazem 70,6\% da arborização total. Dessas, destaca-se Melia azedarach com 18,1\%, Ligustrum lucidum com 11,6\% e Lagerstroemia indica, 8,3\%, como as espécies mais freqüentes.

SANTOS \& TEIXEIRA (1990) constataram esse fato ao fazerem o levantamento no Bairro Centro de Santa Maria onde apenas 5 espécies abrangem mais de $70 \%$ de sua arborização.

Considerando os riscos de pragas e doenças, GREY \& DENEKE (1978) recomendam que cada espécie utilizada na arborização de ruas não atinja mais que $15 \%$ da população total.

Numa perspectiva muito ampla e generalizada da arborização de cidades brasileiras, observase uma certa uniformidade quanto ao emprego de certas espécies, o que se pode supor ser conseqüência normal de uma cidade procurar imitar a arborização de outra. Vem daí a pouca diversidade, concentrando-se a maioria em um número reduzido de espécies, sempre acompanhadas dos mesmos problemas (SOUZA, 1994).

Do total de exemplares identificados no Conjunto Habitacional Tancredo Neves, 1.568 são 
espécies exóticas e 1.220 nativas

KLEIN (1985) afirma que o sucesso obtido, por meio da introdução das espécies exóticas, se deve a fatores como a adequada seleção das espécies, metodologia silvicultural desenvolvida e grande facilidade de coleta de sementes, porém, sendo as nativas o resultado de seleção durante muitos séculos, elas representam as mais adequadas para manter a dinâmica do solo e clima regional.

Sob o aspecto botânico, a arborização urbana em nosso meio, é um campo com possibilidades ilimitadas de pesquisas, bastando dizer que na flora brasileira existem de cinco a seis mil árvores merecedoras de estudo e experimentação, mas o contingente atualmente introduzido em arborização não chega a alcançar cem espécies (MELLO FILHO, 1985).

Quanto ao porte das espécies vegetais, destaca-se o item jovem como o mais freqüente, com $50,2 \%$, seguidos pela muda, $40,7 \%$ e adulta, $9,0 \%$. Os valores acentuados, encontrados nas categorias jovem e muda, deve-se a um processo lento de urbanização que está sendo completado pelos próprios moradores (arborização, muros, calçadas, etc.) e por ser um Conjunto Habitacional com apenas 9 anos de habitação.

MARTINS et al. (1992) observaram que cerca de $41 \%$ das árvores plantadas em Viçosa (MG) apresentaram-se como jovens.

Com relação a área livre a situação apresentada indica que a vegetação encontra-se em sua maioria, 49,5\%, na condição restrita.

Em Viçosa, MARTINS et al. (1992), encontraram uma situação semelhante, em que predominou dentre as quatro condições, a restrita com $21,2 \%$ e com quantidade maior de inexistente $(9,8 \%)$ do que ampla $(5,9 \%)$.

A área adequada para um bom desenvolvimento das plantas não deve ser inferior a $1,0 \mathrm{~m}^{2}$ (CESP, 1988), a nível de Brasil, pois nos Estados Unidos da América é indicado 6,0 m², o ideal para uma suficiente aeração e irrigação natural das raízes do vegetal (WYMAN, 1972).

Em função da arborização ser muito recente e no porte dos vegetais predominar as condições muda e jovem, a avaliação do comportamento do sistema radicular, indicou que os maiores valores foram apresentados pela condição profundos sem danos com 93,2\% enquanto que profundo com danos, superficial sem danos e superficial com danos, com 4,0\%, 2,4\% e 0,3\%, respectivamente.

Em arborização de ruas é aconselhado o uso apenas de espécies cujas raízes cresçam em profundidade (MIRANDA , 1970; SANTIAGO , 1970; SOUZA, 1973).

No que tange a condição física e sanitária, o item satisfatório é o que predomina, 52,1\%, com destaque para as espécies Melia azedarach (10,4\%), Ligustrum lucidum (6,9\%) e Citrus sinensis $(3,4 \%)$.

MILANO (1992) demonstrou que em Vitória-ES, os percentuais, na condição satisfatória, são superiores a 73\%, sendo que em Curitiba-PR e Maringá-PR estão em segundo lugar, com 34,6\% e $33,1 \%$, respectivamente.

Mediante uma avaliação individual da vegetação, foi possível determinar as suas necessidades de tratamentos no Conjunto, sendo que eles, em valores percentuais, são controle fitossanitário, 4,8\%; poda leve, 44,0\%; poda pesada, $8,4 \%$; reparo de danos físicos, $24,8 \%$; remoção com reposição, 4,1\%; remoção sem reposição, 5,6\%; nenhuma necessidade de tratamento, 8,3\%.

Os índices totais, observados aqui, são semelhantes aos encontrados por MILANO (1992), em Vitória-ES, quanto à poda leve $(52,3 \%)$ e remoção $(6,0 \%)$, em Maringá-PR, poda leve $(51,5 \%)$, controle fitossanitário $(6,7 \%)$ e em Curitiba-PR, para poda pesada $(13,8 \%)$.

Ciência Florestal, v. 9, n. 2, 1999 
O presente estudo verificou que $46,0 \%$ dos danos ocasionados ao vegetal é por meio da poda, $12,5 \%$ por vandalismo, $5,3 \%$ por tutor, $4,1 \%$ por acidentes e $2,8 \%$ por obras e construções. É de destacar-se que $29,2 \%$ da vegetação estudada não apresentam qualquer tipo de dano. Esse valor relevante se deve ao fato de que a maioria da vegetação possui porte entre muda e jovem.

SANCHOTENE (1990) declara que os trabalhos de podas, anuais sucessivos ao longo do tempo, danificam muito a arborização de um modo geral. Preocupam, ainda, os trabalhos realizados na vegetação que visam compatibilizá-la com os equipamentos urbanos, especialmente com redes aéreas elétrica e telefônica.

Essa relação define o grau de compatibilidade entre o porte da vegetação e o espaço físico disponível para o seu crescimento adequado, considerando-se a fiação aérea, largura das calçadas, existência de afastamento predial, postes e outros vegetais próximos. Para o total observado, constatou-se que $44,9 \%$ é compatível, $36,0 \%$ medianamente compatível, $11,8 \%$ pouco compatível e $7,3 \%$ incompatível .

Esses valores são respaldados pela relação com o porte predominante, jovem e muda, mas também pelas condições de infra-estrutura existente, como recuo uniforme e largura de calçadas.

A compatibilidade da vegetação é fator determinante nas intervenções silviculturais futuras, como a poda para adequação ao espaço tridimensional onde está instalada, assim como na sua própria sobrevivência.

A falta de participação da comunidade nos programas de arborização de ruas e a falta de conscientização da importância das árvores no ambiente urbano geram sérios prejuízos aos plantios de árvores de ruas (MILANO, 1984).

\section{CONCLUSÃO}

A arborização do Conjunto Habitacional Tancredo Neves apresenta-se, qualitativamente, bastante diversificada em sua composição na qual predomina o porte jovem, com área livre restrita e sistema radicular profundo sem causar danos.

Nos exemplares investigados a condição fitossanitária é satisfatória, porém observa-se a poda como um fator de dano, provocado pelos próprios moradores, embora a compatibilidade com os demais elementos seja predominante.

\section{REFERÊNCIAS BIBLIOGRÁFICAS}

BALMER, W.E. \& ZAMBRANA, J.A. Planting trees in urban areas Rio Piedras, USDA. Forest Service, SOUTHEASTERN AREA, 1977. 2 p. (Urban Forestry Bulletin - Caribbean Area).

BERNATZKY, A. Tree ecology and preservation. Amsterdam: Elsevier Scientific Publishing Company, 1978. 357p.

CESP. Guia de arborização. s.n.t. 1988. 23 p. 
CESTARO, L.A. A vegetação no ecossistema urbano. In: ENCONTRO NACIONAL SOBRE ARBORIZAÇÃO URBANA, 2., 1985, Porto Alegre.Contribuições técnico-científicas... Porto Alegre: PMPA/SMMA, 1985. 255 p. p. 51-56.

GREY, G.M. \& DENEKE, F.J. Urban Forestry. New York: John Wizey, 1978. 279p.

HEISLER, G.M. Trees and human confort in urban areas. J.For., v. 72, n. 8, p. 462-469. 1974.

KLEIN, R.M. Síntese ecológica da floresta estacional da Bacia do Jacuí: importância do reflorestamento com essências nativas (RS). In: CONGRESSO FLORESTAL ESTADUAL, 5., 1985, Nova Prata, Anais... Nova Prata: PMNP,1985. 872 p. p.265-278.

LAPOIX, F. Cidades verdes e abertas. In: ENCICLOPÉDIA DE ECOLOGIA. São Paulo, EDUSP, 1979. 479 p. p. 324-336.

LOMBARDO, M.A. Vegetação e clima . In: ENCONTRO NACIONAL SOBRE ARBORIZAÇÃO URBANA, 3.,1990, Curitiba. Anais... Curitiba: FUPEF, 1990. 368 p. MARTINS, S.V; PAIVA, H.N. de; SOARES, C.P.B. e JACOVINE, L.A.G. Avaliação quali-quantitativa da arborização de ruas de Viçosa - MG.In: ENCONTRO NACIONAL SOBRE ARBORIZAÇÃO URBANA, 4., 1992, Vitória: Anais...Vitória: PMV, 1992. 352p. p. 317 - 326.

MELLO FILHO, L.E. de. Arborização urbana. In: ENCONTRO NACIONAL SOBRE ARBORIZAÇÃO URBANA, 2.,1985, Porto Alegre. Contribuições tecnico - científicas...Porto Alegre: PMPA/SMMA, 1985. 255p. p. 117-127.

MERCANTE, M.A. A vegetação urbana: diretrizes preliminares para uma proposta metodológica. In: ENCONTRO NACIONAL DE ESTUDOS SOBRE O MEIO AMBIENTE, 3., 1991, Londrina. Anais...Londrina: UEL/UEM/UNESP, 1991.774p. p. 51-59.

MILANO, M.S. Avaliação e análise da arborização de ruas de Curitiba-PR. Curitiba: U.F.PR., 1984, 130 p. Dissertação (Mestrado em Engenharia Florestal), Universidade Federal do Paraná, 1984.

Plano diretor de arborização e áreas verdes. Vitória: PMV/SMMA/SMSV, 1992.98 p. MIRANDA, M.A. de L. Arborização de vias públicas. Campinas,s.n. 1970, 47 p. (Boletim Tecnico, 64).

SANCHOTENE, M. do C.C. Situação das áreas verdes e da arborização urbana em Porto Alegre. In: ENCONTRO NACIONAL SOBRE ARBORIZAÇÃO URBANA, 3., 1990, Curitiba, Anais... Curitiba: FUPEF, 1990, 368 p. p. 34-40.

SANTIAGO, A. de C. Arborização de cidades. Campinas: Secretaria da Agricultura, Coordenadoria de Assistência Técnica Integral, 1970. 49 p. (Boletim Técnico SCR, 64).

SANTOS, N.R.Z. dos; TEIXEIRA, I.F. Levantamento quantitativo e qualitativo da arborização do Bairro Centro da cidade de Santa Maria-RS. In: ENCONTRO NACIONAL SOBRE ARBORIZAÇÃO URBANA, 1990, Curitiba. Anais...Curitiba: FUPEF, 1990. 368 p. p. 263-276.

SCHUBERT, T.H. Trees for urban use in Puerto Rico and The Virgin Islands. U.S. For. Serv. Gen. Tech. Rep.SO-27, 1979. 91 p. 
SOUZA, H.M. de. Arborizacão de ruas. São Paulo: Secretaria da Agricultura, Coordenadoria de Pesquisa Agropecuária, Instituto Agronômico, 1973. p 109-134 (Boletim, 204).

Algumas espécies nativas para arborização de vias públicas. In: CONGRESSO BRASILEIRO DE ARBORIZAÇÃO URBANA, 2.,1994, São Luis do Maranhão, Anais...São Luis: SBAU, 1994. 613 p. p. 67-74.

WYMAN, D. Parks, malls roadsides: public area plantings. In: Landscape for living - THE YEARBOOK AGRICULTURE, 1972. Washington: USDA, 1972. p. 77-86. 
ISSN 0103-9954

CRESCIMENTO EM ALTURA DE Araucaria angustifolia (Bert.) O. Ktze. EM TRÊS SÍTIOS NATURAIS, NA REGIÃO DE CANELA - RS

\title{
HEIGHT GROWTH OF Araucaria angustifolia (Bert.) O. Ktze. ON THREE NATURAL SITES, AT REGION OF CANELA - RS
}

\author{
Luciano Weber Scheeren ${ }^{1}$ César Augusto Guimarães Finger ${ }^{2}$ \\ Mauro Valdir Schumacher ${ }^{2}$ Solon Jonas Longhi ${ }^{3}$
}

\begin{abstract}
RESUMO
Este trabalho teve como objetivos o estudo do crescimento da altura dominante em função da idade em três sítios naturais, e a determinação da eficiência da classificação natural de sítios para Araucaria angustifolia (Bert.) O. Ktze. em um plantio na região de Canela, RS. Para o ajuste dos dados de altura e idade, obtidos mediante análise de tronco, utilizou-se a equação de Richards de dois e de três coeficientes, resultando o modelo com três coeficientes mais eficiente para o ajuste dos dados das doze árvores dominantes amostradas nos três sítios naturais em estudo. Obteve-se como resultado sete grupos de árvores dominantes com diferentes tendências de crescimento, demonstrando que a classificação natural de sítios não detectou, de maneira precisa, o efeito das variáveis ambientais no crescimento em altura de Araucaria angustifolia.
\end{abstract}

Palavras-chave: Araucaria angustifolia, sítio, crescimento em altura.

\begin{abstract}
This work has had as its principal objectives the study of dominant height growth considering its age in three natural sites, and the determination of natural sites classification efficacy for the Araucaria angustifolia (Bert.) O. Ktze. in a planting stand in Canela, RS. For height and age data adjustment, determined through stem analysis, it was used the RICHARDS (1959) non-linear mathematics model, with two and three coefficients, resulting the three coefficient model as the most efficient to data adjustment of twelve dominant tree sampled on three natural sites in study. Seven groups of dominant trees with different trends growth were obtained, indicating that the natural sites classification did not detect with accuracy the effects of environmental variables on height growth of Araucaria angustifolia.
\end{abstract}

Key words: Araucaria angustifolia, site, height growth.

1. Engenheiro Florestal, Doutorando do Programa de Pós-Graduação em Engenharia Florestal, Centro de Ciências Rurais, Universidade Federal de Santa Maria, CEP: 97105-900, Santa Maria. (RS).

2. Engenheiro Florestal, Dr., Professor Adjunto do Departamento de Ciências Florestais, Centro de Ciências Rurais, Universidade Federal de Santa Maria, CEP: 97105-900, Santa Maria. (RS).

3. Engenheiro Florestal, Dr., Professor Titular do Departamento de Ciências Florestais, Centro de Ciências Rurais, Universidade Federal de Santa Maria, CEP: 97105-900, Santa Maria. (RS). 


\section{INTRODUÇÃO}

A Araucaria angustifolia (Bert.) O. Ktze. constitui a mais importante essência florestal nativa da economia madeireira do sul do Brasil e também a mais valiosa conífera de ocorrência natural no País.

Apesar da importância da espécie, ela está atualmente ameaçada de extinção. A exploração excessiva, sem a devida reposição, tem sido apontada como a principal razão dessa ameaça. Entretanto, outra importante causa da provável extinção é geralmente ignorada: a falta de conhecimento do comportamento e requisitos silviculturais da espécie.

Um dos aspectos mais problemáticos da Araucaria angustifolia, como espécie para reflorestamento, está representado pela pouca plasticidade em relação às suas exigências edáficas. Observa-se que, dentro de sua área de ocorrência natural, somente $25 \%$ da superfície dessa área apresenta condições economicamente vantajosas para o seu cultivo (IBDF, 1971). No seu habitat natural as matas de Araucaria angustifolia crescem em diferentes tipos de solo, não sendo essa circunstância suficiente para considerar que tais associações de solos sejam todas aptas para o reflorestamento com esta espécie.

Em razão de plantios frustados de espécies nativas como araucária, aliado às crescentes necessidades de madeira, ocorreu a introdução de espécies florestais de crescimento rápido e baixas exigências edáficas, como as espécies de pinus e eucalipto cultivadas no Brasil, abrindo caminho para florestamentos rentáveis nas áreas, até então, consideradas como impróprias para o cultivo de florestas. Esse fato se evidenciou principalmente nas últimas décadas e prossegue até hoje, enquanto a Araucaria angustifolia mostra presença cada vez mais reduzida, pois a tendência dessas espécies, de rápido crescimento, ocuparem as áreas de distribuição natural da Araucaria angustifolia acentua- se, mesmo nos locais com melhores solos.

Nota-se, portanto, a necessidade de conhecer-se a capacidade produtiva de cada sítio, anteriormente à decisão do cultivo de araucária ou mesmo de outras espécies florestais. Tal informação é de vital importância para que se obtenha sucesso em empreendimentos desse nível, que envolvam longas rotações e elevados custos de implantação.

A escolha de espécies mais convenientes, para o cultivo em uma determinada área, deve estar baseada no habitat propriamente dito, isso é, nas condições naturais que a espécie está sujeita para o seu desenvolvimento. A determinação de quais as características do ambiente que influenciam, de maneira quantitativa, o crescimento de araucária permanece desconhecida. Geralmente, a escolha das espécies para um determinado habitat é feita em grandes classes de sítios, sujeitando tão importante decisão a grandes possibilidades de erro, ou seja, da escolha de espécies que não sejam economicamente viáveis para tais habitats.

A escolha da Araucaria angustifolia deve-se ao fato dessa espécie representar um importante segmento da economia madeireira da região sul do Brasil, aliado à reduzida plasticidade que a espécie apresenta com relação aos habitats para o seu desenvolvimento e à contínua redução das suas reservas naturais.

Este trabalho teve como principais objetivos: (1) o estudo do crescimento da altura 
dominante em função da idade, constituindo a variável dendrométrica que melhor expressa a qualidade do sítio; e (2) a determinação da eficiência da classificação natural de sítios para Araucaria angustifolia (Bert.) O. Ktze. em um plantio na região de Canela, RS.

\section{REVISÃO BIBLIOGRÁFICA}

\section{Caracterização da espécie}

A Araucaria angustifolia (Bert.) O. Ktze. é uma espécie nativa, conhecida como pinheirobrasileiro, pinheiro-do-paraná e/ou pinho, no mercado interno. Apresenta madeira de inúmeras utilizações. É de crescimento médio, quando comparada a espécies exóticas, e foi considerada a conífera nativa de maior expressão econômica no País.

Para HUECK (1972), a região de ocorrência natural de araucária encontra-se especialmente nos Estados do Rio Grande do Sul, Santa Catarina, Paraná e São Paulo. No Rio de Janeiro e Minas Gerais há ocorrências isoladas, sendo que uma pequena área penetra na Argentina.

No Brasil, para o autor acima mencionado, a ocorrência dessa espécie se limita entre as

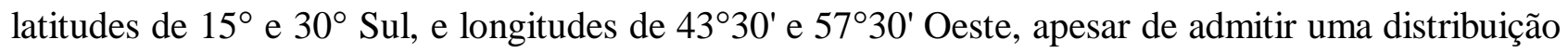
irregular.

GOLFARI (1967) situa a área de ocorrência natural em um clima temperado no qual a temperatura média anual varia de 13 a $18^{\circ} \mathrm{C}$, caracterizando-se por verões frescos e invernos relativamente frios, com mínimas próximo a $-8^{\circ} \mathrm{C}$. VAN GOOR (1965), diz que os tipos climáticos de Köppen, $\mathrm{Cwb}, \mathrm{Cfb}$ e Cfa, caracterizados por apresentarem chuvas bem distribuídas durante o ano, não são limitantes para o crescimento de araucária, porém, altitudes abaixo de 600 metros são consideradas críticas para a espécie.

Segundo Romariz apud CASSOL (1982), a espécie ocorre sobre os mais variados tipos de solo, desde os mais pobres como os Campos Gerais do Paraná (derivados de arenitos), até os solos escuros e férteis (derivados de basalto).

\section{Classificação de sítios}

Nos trabalhos de planejamento florestal, a delimitação dos sítios naturais assume importância especial, uma vez que as unidades de produção possuem características ecológicas próprias e, em conseqüência, crescimento semelhante.

Para VAN LEAR \& HOSNER (1967), GARCIA (1970) e RUSSEL (1971), o conhecimento da capacidade produtiva de uma determinada área é requisito básico para o planejamento da maioria das intervenções no povoamento, escolha da espécie, formação dos povoamentos, manejo e aproveitamento dos recursos florestais, embora declarem que ela é de difícil determinação.

A qualidade do sítio é definida como sendo "uma área considerada segundo seus fatores ecológicos em relação à sua capacidade de produzir povoamentos florestais ou outra vegetação, sob 
a combinação de condições biológicas, climáticas e edáficas" (Sociedade Americana de Florestas apud DAVIS, 1954).

Segundo HEIBERG \& WHITE (1956), o habitat, no sentido ecológico, pode ser considerado como a definição de qualidade de sítio no sentido silvicultural, ou seja, "a soma das condições efetivas sob as quais vive uma planta ou uma comunidade de plantas".

Sammi apud SCHNEIDER (1993) apresenta o conceito de sítio florestal sinteticamente definido como "a classificação de uma área quanto à sua capacidade de produzir madeira".

De acordo com SPURR (1952), os fatores do meio atuam em conjunto, com interações e relações complexas, sobre o crescimento das árvores. A qualidade do sítio não depende de um fator nem de todos os fatores do meio, mas dos fatores efetivos e das interações entre eles. Em geral, a umidade do solo é o fator mais relacionado com a qualidade do sítio.

Esse autor destaca que, contudo, se deve sempre ter em mente que a qualidade do sítio é uma característica dinâmica e, freqüentemente, ao longo do tempo, alguns fatores do sítio podem ser influenciados pelo clima e pela atividade antrópica, como a silvicultura. Entre os principais objetivos da avaliação da qualidade de sítio podem ser considerados: (a) estimativa do rendimento total dos povoamentos; (b) planejamento e execução de trabalhos de pesquisa; (c) programação e execução de trabalhos de manutenção (limpeza) das plantações existentes; (d) extensão da classificação da qualidade do sítio em áreas a serem plantadas, para a seleção adequada de espécies.

Além disso, o autor declara que: (1) os custos de produção podem variar segundo a qualidade do sítio, por exemplo, os trabalhos de limpeza, geralmente, devem ser efetuados com maior freqüência nos melhores sítios; (2) a idade na qual se realiza o primeiro desbaste também varia segundo a qualidade do sítio.

Diferentes métodos podem ser empregados para realizar a classificação de sítios: (1) o método ambiental que envolve fatores físicos, químicos, topográficos e climáticos da região; ou (2) o método dendrométrico que realiza a classificação dos sítios a partir da capacidade produtiva de cada unidade, expressa pela altura dominante. Outra alternativa consiste na integração dos dois métodos, de modo a correlacionar variáveis dendrométricas com os fatores do ambiente (Campbel, Kreutzer, Grey, Gassana \& Loewestein apud SELLE, 1993).

De acordo com SCHNEIDER (1993), a classificação de sítios, de forma geral, trata de descrever o crescimento de uma espécie sob a influência de algum ou alguns fatores do ambiente, quer sejam ecológicos, de tempo sob condições ecológicas próprias, ou por meio da combinação de ambos. Na definição dos sítios naturais, procura-se informações sobre aspectos climáticos que, juntamente com os fatores edáficos e fisiográficos, poderão determinar a qualidade dos habitats. No entanto, uma das tarefas mais difíceis é a escolha e avaliação dos parâmetros que influem no crescimento da vegetação, sua relação e quantificação, dentro de um sistema harmônico. Assim, os métodos utilizados, para inventariar os sítios, são variados e condicionados rigorosamente pelo local e, principalmente, pelo clima e pelo solo.

Para esse autor, por meio da classificação de sítios em função de elementos dendrométricos, busca-se descrever o desenvolvimento de uma variável dendrométrica através do tempo, utilizando-

Ciência Florestal, v. 9, n. 2, 1999 
se, para isso, uma variável de fácil medição. Esse crescimento, após modelado matematicamente, pode ser padronizado, passando a caracterizar uma classe que pode ser baseada na altura, volume, incremento, entre outras, como variável resposta e idade como variável de entrada.

Há muito tempo, que pesquisadores da ciência florestal procuram encontrar um parâmetro dendrométrico ideal para ser utilizado como índice de sítio. Essa procura é justificada pelo fato de que, somente, um elemento dendrométrico pode indicar diretamente a produção de uma espécie num determinado local (SCHNEIDER, 1993).

Um bom parâmetro indicador de sítio deve Ter, fundamentalmente, as seguintes características, de acordo com BURGER (1976): (a) ser de fácil determinação no campo; (b) possuir boa correlação com a produção volumétrica; (c) indicar a qualidade de sítio para todas as idades do povoamento; (d) ser independente da densidade do povoamento.

A capacidade produtiva de um local, em geral, pode também ser determinada pela relação altura e idade, representando uma boa medida da qualidade do sítio, sendo expressa em termos de índice de sítio. Embora o volume seja o parâmetro que reflete com maior precisão a qualidade do sítio, a altura dominante é empregada em virtude da facilidade para ser determinada e por ser pouco influenciada pelo espaçamento e pelos desbastes realizados ao longo da rotação (FAO, 1981).

A construção de curvas de altura em função da idade, correspondentes à diferentes classes de sítio, é o primeiro passo na determinação de modelos de produção e crescimento (ALDER, 1980).

Baseados nessa metodologia, os conceitos de índices de sítio foram primeiramente desenvolvidos e utilizados na Alemanha no século XIX, e vêm sofrendo, ao longo dos anos, modificações na forma de sua determinação, sendo, atualmente, obtidos como expressão da altura média das árvores dominantes, ou a média das dominantes e codominantes, relacionadas com uma idade índice (MACHADO, 1978).

Segundo o mesmo autor, inicialmente a determinação das curvas de índice de sítio era feita a mão livre sobre dados de altura e idade obtidos em parcelas permanentes e temporárias. Nesse processo é traçada uma curva média entre a nuvem de pontos e, a seguir, de forma, aproximadamente, paralela às tendências das parcelas, é traçada uma curva na extremidade inferior e outra na parte superior da curva média. A partir daí, interpola-se curvas entre a curva superior e a central e entre a central e a inferior (curvas monomórficas).

Clutter et al. apud SELLE (1993) afirmaram que, para a construção de curvas polimórficas, o processo de construção exige repetidas medições em intervalos sucessivos de tempo (parcelas permanentes), ou mediante a análise de tronco de espécies que apresentam anéis de crescimento visíveis. Com os dados de altura e idade ajusta-se uma função para cada árvore, sítio natural ou parcela amostrada.

Atualmente, a altura do povoamento, para a classificação do sítio, é utilizada em quase todo o mundo, definida pelos índices de sítio. Entende-se como "índice de sítio" somente uma classificação de sítio mediante a altura, enquanto que todos os outros métodos de classificação originam "classes de sítio".

A altura, como base para a classificação de sítios, foi proposta inicialmente na Alemanha, 
sendo indicados como o elemento dendrométrico mais adequado para a determinação da qualidade do sítio. Isso é em razão da altura de uma árvore estar condicionada a fatores de natureza hereditária, sendo pouco influenciada pela densidade do povoamento. A atividade fotossintética parece ter pouca influência direta no desenvolvimento da altura, que conseqüência do crescimento em altura ser processado às custas das reservas de hidratos de carbono acumuladas nas folhas velhas e ramos finos das extremidades (SCHNEIDER,1993).

O principal motivo que faz com que se despreze a altura média e se adote a altura dominante é em virtude da grande influência do desbaste que eleva, automaticamente, o valor da altura média com o corte das árvores dominadas do povoamento. Por outro lado, a altura dominante não sofre influências do desbaste, a não ser que se aplique um desbaste por alto que altere o estrato superior. A altura dominante ainda possui a vantagem de estar fortemente correlacionada com a produção volumétrica, sendo fundamental para a construção de tabelas de produção.

A altura dominante de um povoamento é apenas uma definição e não um verdadeiro valor absoluto. Inúmeras são as definições existentes para a altura dominante, dentre várias destacam-se as seguintes (SCHNEIDER,1993):

a) Altura média das 100 árvores mais altas por hectare (HART);

b) altura média de $20 \%$ das árvores mais altas por hectare (WEISE);

c) altura média das 100 árvores mais grossas / ha (ASSMANN);

d) altura média das dominantes e codominantes (MEYER);

e) altura média das 30 árvores mais altas por hectare (LEWIS);

f) altura de Lorey das árvores mais grossas, até $12 \mathrm{~m}^{2}$ de área basal / ha (Pollanschütz apud FINGER, 1992).

Algumas dessas definições foram comparadas em uma pesquisa instalada nas Florestas Nacionais de Três Barras-SC, Capão Bonito-SP e Irati-PR. O estudo foi realizado em povoamentos de Araucaria angustifolia e Pinus elliottii de várias densidades e idades diferentes. Foi constatado que não há diferenças significativas entre as definições de altura. Isso levou FISHWICK (1975) a recomendar a mais simples delas, ou seja, a altura média das 100 árvores mais grossas por hectare.

\section{Funções para descrição do crescimento}

O ajuste do crescimento da altura, em função da idade, pode ser realizado por uma grande variedade de modelos matemáticos, lineares ou não-lineares.

Alguns modelos apresentavam dificuldades na sua utilização, como a função não-linear de RICHARDS (1959) e a função logística, anteriormente ao desenvolvimento e popularização da computação eletrônica que se verificou nos últimos anos, embora mostrassem um bom ajuste dos dados.

Segundo FINGER (1992), a função de Richards apresenta como vantagem a possibilidade de obtenção de uma interpretação lógica, além de ser bastante flexível, adaptando-se bem ao 
desenvolvimento de diferentes variáveis dendrométricas.

Esse mesmo modelo foi empregado por vários autores, por causa das suas características, ou seja, a forma sigmoidal, passagem pela origem e tendência a uma assíntota superior finita (SELLE, 1993).

Para Batista \& do Couto apud SELLE (1993), tais características têm significação biológica, o que torna o modelo muito adequado para uso em classificações de sítios.

Para a comparação e seleção dos modelos matemáticos utiliza-se critérios estatísticos. De uma forma geral, a maioria dos autores, segundo FINGER (1992), cita o coeficiente de determinação $\left(R^{2}\right)$ e o erro padrão da estimativa $\left(S_{\mathrm{yx}}\right)$, usados em conjunto, como critérios de análise mais empregados. O coeficiente de determinação expressa a quantidade de variação total explicada pela regressão, sendo que, no momento da seleção dos modelos, escolhe-se o modelo que apresentar maior valor de $\mathrm{R}^{2}$. Já o erro padrão de estimativa é uma medida que expressa a dispersão entre os valores observados e estimados pela regressão, sendo a melhor equação, de acordo com essa estatística, aquela que apresentar o menor valor de $S_{\mathrm{yx}}$. Também, segundo o autor, se deve analisar a distribuição dos resíduos para a seleção segura de uma equação.

\section{MATERIAL E MÉTODO}

\section{Localização da área de estudo}

Os dados para o presente estudo foram obtidos na Floresta Nacional de Canela (FLONA Canela - RS), localizada no município de Canela, Rio Grande do Sul. A área de estudo situa-se entre as coordenadas geográficas $29^{\circ} 18^{\prime}$ latitude sul e $50^{\circ} 53^{\prime}$ longitude oeste.

A região fisiográfica, onde está situada a Floresta Nacional de Canela, é denominada de Encosta Superior do Nordeste, sendo zona de ocorrência de floresta natural de araucária.

\section{Climatologia e edafologia}

O clima dominante na região, segundo o sistema KÖPPEN, é do tipo "Cfb1", temperado úmido (MORENO,1961). De acordo com IPAGRO (1989), a região do município de Canela possui temperatura média anual de $14,8^{\circ} \mathrm{C}$, precipitação média anual de $1.821 \mathrm{~mm}$ e umidade relativa do ar média de $80 \%$.

Segundo MOTA et al. (1971), os ventos dominantes na região são alísios, ou seja, sopram na direção do mar para a terra. O sentido predominante do vento é sudoeste (SW), embora ocorram ventos de nordeste $(\mathrm{NW})$ durante os meses de maio a agosto. Na região ocorre freqüentemente a formação de geadas, podendo, ocasionalmente, ocorrer precipitação de neve.

De acordo com CARRARO et al. (1974), e BRASIL (1973), a região enquadra-se no grupo de solo São Bento que abrange as formações da Serra Geral, Botucatu e Rosário do Sul. Especificamente, o local em estudo encontra-se na formação Serra Geral caracterizada por derrames 
de lava basáltica.

O solo da região enquadra-se na unidade de mapeamento Bom Jesus, sendo pouco desenvolvido e classificado como Cambisol Húmico. Suas principais características são: álico, textura argilosa, relevo ondulado a forte ondulado e substrato basáltico. Predominam solos profundos, moderadamente drenados, de coloração escura e bruno avermelhada, friáveis, ácidos e com baixa saturação de bases, apresentado teores elevados de alumínio trocável e teores altos de matéria orgânica, chegando a 5\% no horizonte A. A fertilidade natural do solo é elevada.

A variação mais freqüente, nesses solos, diz respeito à ocorrência de perfis mais rasos, com horizonte $\mathrm{B}$ menos profundo, perfis litólicos, perfis hidromórficos de altitude e afloramentos de rochas.

\section{Características da floresta}

A Floresta Nacional de Canela apresenta uma área total de 517,7 hectares, sendo 128,8 ha de florestas nativas $(29,4 \%), 280,5$ ha de florestas plantadas $(53,3 \%)$ e 108,3 ha de áreas nãoestocadas (17,2\%). A área plantada divide-se em 129,9 ha de Araucaria angustifolia (46,3\%), 114,3 ha de Pinus sp. (40,7\%), 29,4 ha de floresta mista de Araucaria angustifolia e Pinus elliottii $(10,8 \%)$ e 6,0 ha de plantações de Eucalyptus sp. (2,2\%).

Os espaçamentos utilizados inicialmente nos povoamentos, eram reduzidos, apresentando, conseqüentemente, talhões com grande densidade inicial. No caso da Araucaria angustifolia, os plantios eram feitos diretamente no campo, utilizando duas ou três sementes por cova, em espaçamentos reduzidos.

Os replantios, em número de um ou mais, foram realizados nos casos de baixo índice de sobrevivência dos plantios. Alguns talhões apresentam partes em que a implantação inicial foi feita com Araucaria angustifolia, que não obteve êxito, sendo posteriormente substituídos por povoamentos de Pinus sp.

Os plantios iniciais da Floresta Nacional de Canela datam de 1948 e continuaram pela década de 50 voltados à Araucaria angustifolia. Na década de 60 foram realizados principalmente plantios de Pinus elliottii, época que coincide com a expansão de culturas de exportação como a soja e da fronteira agrícola como um todo.

Entretanto, os reflorestamentos tiveram cuidados limitados, apenas no sentido de preservar o patrimônio florestal. Esses povoamentos foram depreciados pela falta de intervenções técnicas como desbastes, necessários em virtude dos reduzidos espaçamentos iniciais utilizados. Nessas áreas foi realizado apenas o que se denominou manejo moderado, com a colheita florestal feita sem-objetivos claros ou bem-definidos.

O histórico dos povoamentos de araucária mostra que eles sofreram intervenções silviculturais de baixa intensidade. Embora alguns talhões apresentem um número reduzido de indivíduos, esse número baixo de indivíduos é uma conseqüência do baixo índice inicial de sobrevivência.

As características de cada sítio natural, segundo IBAMA (1989), são descritas a seguir:

Ciência Florestal, v. 9, n. 2, 1999 
Sítio I : localiza-se nas planícies, partes inferiores das encostas e planos superiores do relevo, abrangendo 46,6\% da área total interna dos talhões. O húmus presente nesse sítio é do tipo Moder. O solo apresenta uma profundidade mínima de $60 \mathrm{~cm}$, porém com raríssimos afloramentos de rocha, textura franco argilosa, estrutura granular a blocos subangulares, friável, pegajoso, plástico, moderadamente drenado e de coloração escura.

Sítio II : abrange as áreas mais íngremes, as partes superiores das encostas, bem como as áreas com afloramento de rochas e representa $47,3 \%$ das áreas internas dos talhões. O húmus é do tipo Moder. O solo caracteriza-se por ser raso, apresentando uma camada de impedimento ao desenvolvimento das raízes a partir dos $20 \mathrm{~cm}$, com coloração escura, argiloso, granular, friável, pegajoso e com pedras soltas na superfície.

Sítio III : apresenta um relevo pouco movimentado em forma de depressão irregular com afloramento de rochas individualizadas e ocupa 3,9\% das áreas internas dos talhões. O húmus é do tipo Moder. O solo desse sítio é profundo com presença de resíduos de rochas ao longo do perfil, cor marrom avermelhada, franco argiloso, granular, com estrutura em blocos, friável, plástico, pegajoso e com boa porosidade.

\section{Metodologia para levantamento de dados}

Foram traçadas três linhas, com 150 metros de comprimento cada, sobre o mapa da classificação natural de sítios realizada no povoamento pelo IBAMA (1989), de forma que cada linha ficou sobre uma das classes naturais de sítio em estudo. Sobre cada linha foram locadas quatro unidades amostrais, dispostas de maneira eqüidistante. Dessa forma, obteve-se doze unidades amostrais para as três classes naturais de sítio em estudo.

As unidades amostrais foram temporárias utilizadas somente para uma única coleta de dados. O método de Bitterlich foi utilizado para a locação das unidades amostrais, sendo as árvores selecionadas com probabilidade proporcional ao seu diâmetro (Amostra por Contagem Angular). Para o desenvolvimento desse método procedeu-se com base em um ponto fixo, fazendo-se um giro de 360 graus, comparando o ângulo selecionado com os indivíduos observados. No caso do diâmetro da árvore ser maior ou igual ao ângulo selecionado, ela é incluída na unidade amostral. Se o diâmetro da árvore for menor que o ângulo selecionado, ela não é incluída na unidade amostral.

O ângulo selecionado para esse levantamento foi de $2^{\circ} 17^{\prime} 32^{\prime \prime}$ que corresponde ao Fator de Área Basal (FAB) quatro e à banda quatro do relascópio de Bitterlich, dessa forma, cada árvore, selecionada em uma unidade amostral (ACA), representa uma área basal de $4 \mathrm{~m}^{2} / \mathrm{ha}$.

Foi determinada em cada ACA a árvore de altura dominante média, segundo o conceito de Pollanschütz $\left(\mathrm{h}_{\text {Poll }}\right)$. Para um fator de área basal igual a quatro, a altura média das três árvores de maior diâmetro corresponde à árvore de altura dominante média.

Em cada ACA, a árvore de altura dominante média selecionada, segundo o conceito de Pollanschütz, foi abatida e foram retiradas fatias do tronco com, aproximadamente, $5 \mathrm{~cm}$ de espessura nas alturas de $0,1 \mathrm{~m}, 0,5 \mathrm{~m}, 1,3 \mathrm{~m}$ e, acima disso, a cada $2,0 \mathrm{~m}$ de altura até o diâmetro limite de $5 \mathrm{~cm}$.

Os dados foram processados em programa de computador ANATRO (Análise de Tronco), 
elaborado por SCHNEIDER (1984), do qual se obteve a altura de cada árvore para uma determinada idade.

Os resultados da análise de tronco de cada classe de sítio foram analisados separadamente e comparativamente com as outras classes de sítio, buscando estabelecer as diferenças no crescimento em altura das árvores em um sítio e entre sítios diferentes. Para isso, foi ajustada uma função matemática para descrever o crescimento de cada árvore individualmente.

A análise do crescimento da altura dominante, em função da idade, foi realizada mediante a equação de Richards que apresenta bons resultados para uma grande variedade de fenômenos biológicos, sendo essa equação também citada na literatura como função de Chapman-Richards. Ela foi utilizada na sua forma integral (1), com 3 coeficientes, e na forma reduzida, com apenas dois coeficientes (2):

$$
\begin{aligned}
& Y=A \times\left(1-e^{(-K \times t)}\right)^{R} \\
& Y=A \times\left(1-e^{(-K \times t)}\right)
\end{aligned}
$$

Em que: $\mathrm{Y}=$ Altura dominante $(\mathrm{m})$;

$\mathrm{A}, \mathrm{K}$ e $\mathrm{R}=$ coeficientes;

$\mathrm{t}=$ idade (anos);

$\mathrm{e}=$ logaritmo natural.

Segundo PEDRO BOM \& BRENA (1991), o significado biológico do coeficiente A é a altura total ou assintótica que a planta pode atingir. O coeficiente K expressa uma medida relativa da taxa de crescimento e o coeficiente $\mathrm{R}$ é o responsável pela localização do ponto de inflexão sobre a curva e pela forma da curva sigmóide de crescimento.

Para a seleção do modelo matemático, utilizaram-se as medidas de precisão do coeficiente de determinação $\left(R^{2}\right)$, o erro padrão de estimativa $\left(S_{\mathrm{yx}}\right)$ e a visualização do ajuste gráfico (resíduos), para os modelos de 2 e 3 coeficientes. Foi realizada também a análise da variância entre os dois modelos matemáticos para a seleção entre o modelo com 2 ou 3 coeficientes, e análise de covariância entre as 12 árvores, para verificar o paralelismo das tendências de crescimento.

O coeficiente de determinação $\left(R^{2}\right)$ expressa a quantidade da variação explicada pela regressão. Como o coeficiente de determinação é crescente à medida que se inclui uma nova variável ao modelo matemático, utilizou-se o coeficiente de determinação ajustado $\left(R_{a j}^{2}\right)$, que é ajustado para o número de coeficientes da equação. Eles são obtidos pelas seguintes expressões:

$$
\begin{aligned}
& R^{2}=\frac{\sum\left(\hat{Y}_{i}-\bar{Y}\right)^{2}}{\sum\left(Y_{i}-\bar{Y}\right)^{2}} \\
& R_{A j}^{2}=R^{2} \times\left[\frac{k-1}{n-k}\right] \times\left(1-R^{2}\right)
\end{aligned}
$$


Em que: $\$_{i}=$ Estimativa da variável dependente;

$\mathrm{Y}_{\mathrm{i}}=$ Variável dependente observada;

$\bar{Y}=$ Média da variável dependente;

$\mathrm{k}=$ Número de variáveis independentes da equação;

$\mathrm{n}=$ Número de observações.

Outro parâmetro utilizado para a seleção do modelo matemático foi o erro padrão de estimativa $\left(S_{\mathrm{yx}}\right)$ que mede a dispersão entre os valores observados e estimados pela regressão. Devese destacar que o erro padrão de estimativa somente pode ser utilizado como comparador entre várias equações quando as variáveis dependentes apresentarem mesma unidade. Em razão disso, Meyer apud SCHNEIDER (1998) apresenta o erro padrão em percentagem $\left(\mathrm{S}_{\mathrm{yx}} \%\right)$ como alternativa para a comparação de equações com variáveis dependentes de diferentes unidades. O erro padrão de estimativa e o erro padrão em percentagem são obtidos mediante as seguintes fórmulas:

$$
\begin{aligned}
& S_{y x}=\sqrt{\frac{\left.\sum\left(Y_{i}-\$ \$_{i}\right)^{2}\right)}{n-(k-1)}} \\
& S_{y x} \%=\frac{S_{y x}}{\gamma} \times 100
\end{aligned}
$$

Em que: $\$$

$Y_{i}=$ Variável dependente observada;

$\mathrm{n}=$ Número de observações;

$\mathrm{k}$ = Número de variáveis independentes da equação;

$\gamma=$ Média aritmética da variável dependente.

Dessa forma, será selecionado o modelo matemático que apresentar o maior valor de $\mathrm{R}_{\text {aj }}^{2} \mathrm{e}$ o menor valor de $S_{\mathrm{yx}}$.

No estudo foi considerada como idade-índice a idade de 40 anos.

\section{RESULTADOS E DISCUSSÃO}

\section{Características dendrométricas do povoamento}

Os dados coletados nas Amostras por Contagem Angular (ACA's) realizadas no povoamento de Araucaria angustifolia da Floresta Nacional de Canela, em conjunto com os resultados obtidos na análise de tronco das árvores amostradas, permitem observar as médias para cada sítio e as diferenças entre as ACA's de um mesmo sítio e de sítios diferentes (Tabela 1).

Ciência Florestal, v. 9, n. 2, 1999 
TABELA 1: Valores médios de densidade $(\mathrm{N})$ e área basal $(\mathrm{G})$ por hectare, diâmetro à altura do peito (DAP), altura dominante de Pollanshütz $\left(\mathrm{h}_{\mathrm{Poll}}\right)$, incremento periódico dos últimos cinco anos $\left(\mathrm{IP}_{5}\right)$ e incremento médio anual (IMA), nas ACA's dos diferentes sítios naturais, com idades de 39 a 47 anos.

\begin{tabular}{l|c|c|c|c|c|c|c|c|c}
\hline Sítio & ACA & \multirow{2}{*}{ N/ha } & \multirow{2}{*}{ G/ha } & \multicolumn{3}{|c|}{ Diâmetro $(\mathrm{cm})$} & \multicolumn{3}{|c}{ Altura (m) } \\
\cline { 5 - 10 } & & & & DAP & $\mathrm{IP}_{5}$ & $\mathrm{IMA}$ & $\mathrm{h}_{\text {Poll }}$ & $\mathrm{IP}_{5}$ & IMA \\
\hline III & $1-4$ & 742 & 30 & 31,3 & 1,3 & 0,9 & 18,3 & 0,3 & 0,5 \\
II & $5-8$ & 306 & 26 & 30,7 & 1,2 & 0,8 & 19,2 & 0,4 & 0,4 \\
I & $9-12$ & 289 & 31 & 35,4 & 1,3 & 0,9 & 19,9 & 0,4 & 0,4 \\
\hline
\end{tabular}

Nos dados da Tabela 1, pode-se observar que o incremento médio anual (IMA) e o incremento periódico $\left(\mathrm{IP}_{5}\right)$, medido nos últimos 5 anos anteriores do abate da árvore, em diâmetro e altura são semelhantes nos três sítios em estudo, apesar da maior densidade populacional observada no sítio III. A altura dominante média nos três sítios apresenta pouca diferença, sendo o sítio I ligeiramente superior ao sítio II e este pouco superior ao sítio III, ficando a maior diferença entre o sítio I e o sítio III $(1,6 \mathrm{~m})$.

\section{Definição do modelo matemático}

O ajuste dos dados de altura em função da idade, obtidos por meio de análise de tronco de 12 árvores, mediante a equação de Richards com 2 e 3 coeficientes, mostraram, respectivamente, altos coeficientes de determinação $(0,948$ - 0,999) e valores reduzidos de erro padrão de estimativa $(1,23$ m - 0,20 m). Da mesma forma, a análise gráfica dos resíduos das curvas de altura observada e altura ajustada não mostrou tendências em nenhuma das equações.

Os resultados obtidos permitem afirmar que a equação com 3 coeficientes apresenta, para todas as árvores, o menor erro padrão, bem como maior coeficiente de determinação. A equação com 2 coeficientes mostra valores de erro padrão ligeiramente superiores e coeficientes de determinação pouco inferiores, sendo ambas as equações eficientes.

Embora se constate, em função dos critérios citados anteriormente, uma ligeira superioridade da equação com 3 coeficientes, foi realizada uma análise da variância dos resíduos das duas equações (Tabela 2), de acordo com a metodologia empregada por FINGER (1991).

TABELA 2: Análise da variância dos resíduos dos modelos de Richards com dois e três coeficientes.

\begin{tabular}{l|c|c|c|c}
\hline \multicolumn{1}{c|}{ FV } & GL & SQ & QM & F \\
\hline 3 coeficientes & 456 & 53,325 & 0,117 & 4,44 \\
2 coeficientes & 468 & 298,238 & 0,637 & \\
\hline Diferença & 12 & 244,913 & 0,520 & \\
\hline
\end{tabular}

Em que: FV = Fonte de Variação; $\mathrm{Gl}=$ Graus de liberdade; $\mathrm{SQ}=$ Soma dos Quadrados; $\mathrm{QM}=$ Quadrado Médio; $\mathrm{F}=$ Estatística F de Snedecor.

De acordo com o resultado do teste $\mathbf{F}_{(456,12)}$, calculado na Tabela 2, rejeita-se a hipótese de igualdade entre os dois modelos, pois o valor calculado de $\mathbf{F}(4,44)$ é maior que o valor tabelado 
(2,31), com 95\% de confiabilidade. Dessa forma, deve-se utilizar o modelo matemático de três coeficientes, pois há diferença significativa em nível de 5\% de erro no ajuste dos dados observados.

\section{Estudo das tendências de crescimento}

A comparação das curvas de crescimento, em altura quanto ao paralelismo nos três sítios naturais em estudo, foi realizada pela análise de covariância, utilizando-se todos os valores de altura e idade das árvores amostradas cujo resultado pode ser observado na Tabela 3, e também pela comparação gráfica das curvas.

TABELA 3: Análise de covariância, para as árvores dos três sítios em estudo, para testar o paralelismo das curvas de crescimento de $\mathrm{h}_{\text {Poll }}$ em função da idade.

\begin{tabular}{lrrrrrr}
\hline \multicolumn{1}{c}{ F. V. } & GL & \multicolumn{1}{c}{ SQ } & \multicolumn{1}{c}{ QM } & \multicolumn{1}{c}{ F } & Prob > F \\
\hline Sítio/Árvore & 11 & 2141,5082 & 194,6826 & 94,69 & 0,0001 \\
Idade & 1 & 12663,7865 & 12663,7865 & 6159,34 & 0,0001 \\
Idade (Sítio/Árvore) & 11 & 389,4014 & 35,4001 & 17,22 & 0,0001 \\
Erro & 469 & 964,2787 & 2,0560 & & \\
\hline Total & 492 & 16158,9748 & & \\
\hline
\end{tabular}

O resultado da análise de covariância mostrou que a hipótese de igualdade da inclinação das curvas de crescimento é rejeitada em nível de $5 \%$ de probabilidade de erro, nos diferentes sítios naturais, indicando a não-ocorrência do paralelismo entre as curvas de crescimento em altura das árvores.

Na Figura 1, observa-se as curvas de crescimento da altura dominante em função da idade, ajustadas pela equação de Richards de três coeficientes, para as árvores dos três sítios naturais em estudo.

A diferença significativa de inclinação entre as curvas de crescimento obtida na análise de covariância é comprovada também, observando-se as curvas da Figura 1 na qual nota-se a existência de diferentes tendências de crescimento, inclusive, nas árvores classificadas em um mesmo sítio natural. Verifica-se que as tendências médias de crescimento em altura dominante dos sítios I e II (Figura 1) mostram grande semelhança; porém a tentativa de agrupamento desses sítios naturais em um único grupo mostrou-se inviável. Isso é evidenciado pelo cruzamento das curvas de crescimento 

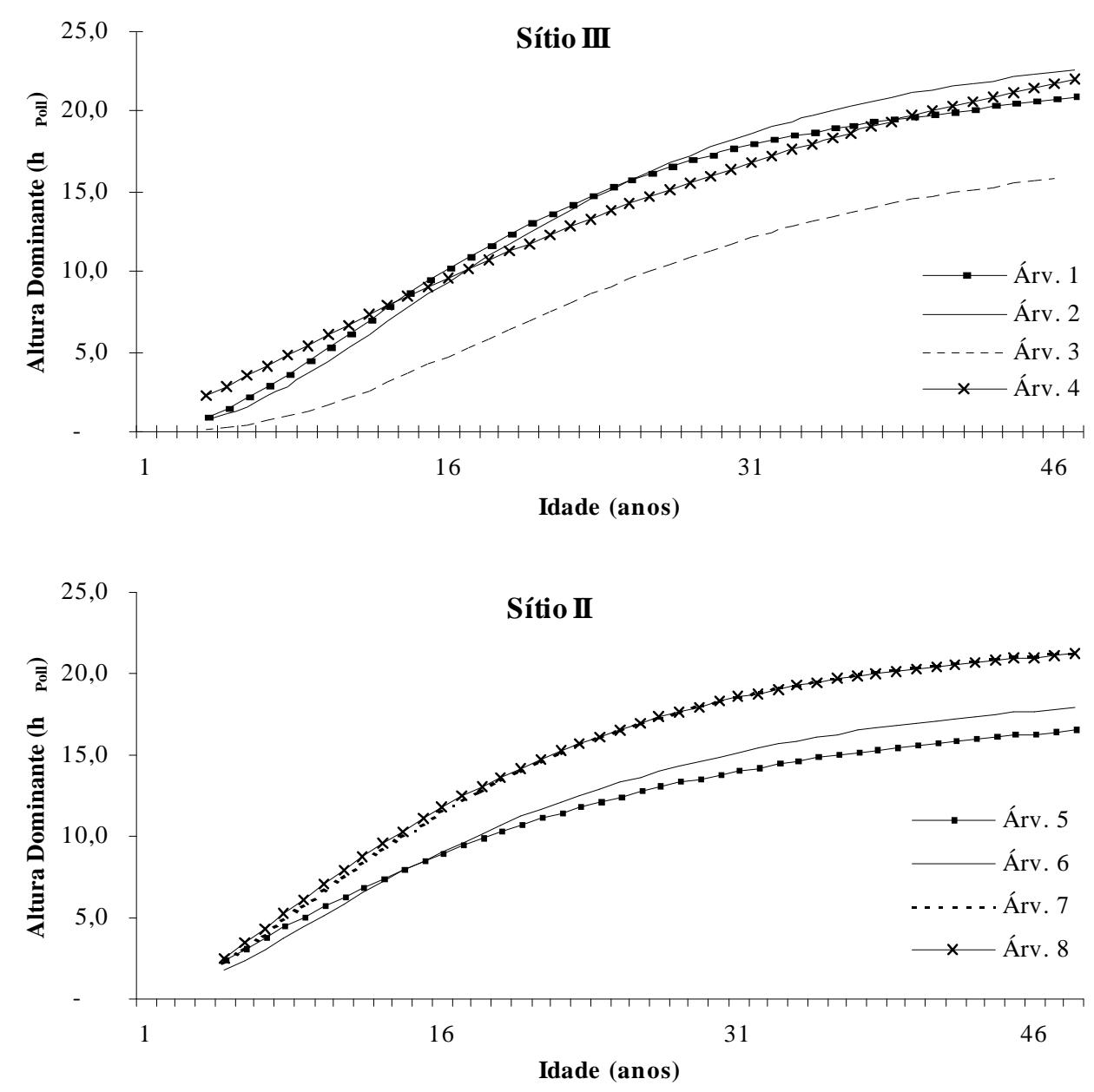

Sítio I

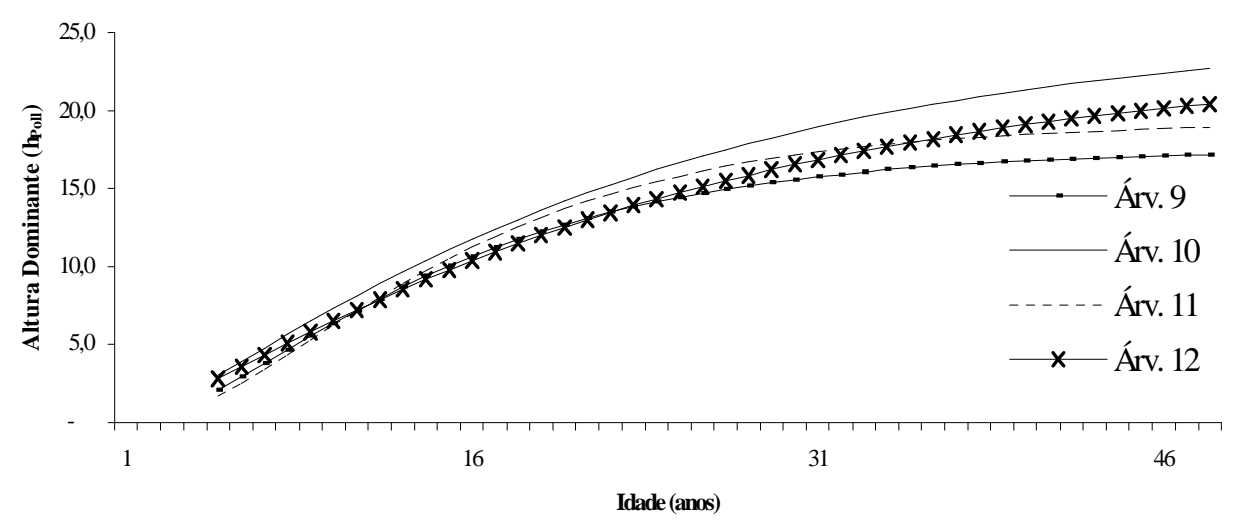

FIGURA 1: Curvas ajustadas de altura dominante em função da idade, para as árvores dos sítios III, II e I. 
das árvores, sendo o desejado que elas fossem paralelas dentro de um mesmo sítio, admitindo-se apenas diferenças de nível entre as ambas.

Dessa maneira, tornou-se necessária uma nova classificação de sítios, separando-se as árvores com tendências de crescimento comum em grupos distintos. Para tanto, mediante a análise gráfica das tendências de crescimento das árvores, procedeu-se a formação de novos grupos.

Nesse procedimento, as árvores integrantes dos grupos foram selecionadas de acordo com o paralelismo das curvas, e as curvas de sítio construídas por meio dos valores médios dos coeficientes $\mathrm{K}$ e R e da reestimativa do coeficiente A, para a idade-índice determinada, tendo sido formados sete novos grupos (Figura 2), nos quais evitou-se o cruzamento entre as curvas de crescimento.

Particularmente no Grupo A, nota-se que a classificação obtida pelas tendências de crescimento das árvores corresponde exatamente ao sítio natural II (árvores 5, 6, 7 e 8), na classificação de sítios realizada pelo IBAMA (1989) para a FLONA de Canela.

Comparando-se o sítio natural I da classificação anterior (Figura 1) com a classificação pelas tendências de crescimento (Figura 2), observa-se que esse sítio, na verdade, constitui dois grupos distintos: o "Grupo B" (árvores 10 e 12) e o "Grupo C" (árvores 9 e 11).

No sítio natural III, foram determinados quatro diferentes padrões de crescimento, compostos pelo Grupo D (árvore 3), Grupo E (árvore 1), Grupo F (árvore 4) e Grupo G (árvore 2), sendo que esses padrões não apresentaram possibilidades de agrupamento com as demais árvores amostradas, por causa da ocorrência de cruzamento nas curvas, o que pode indicar diferenças em nível de microsítio.

Os resultados, apresentados na Figura 2, mostram que a análise de covariância (Tabela 3), realizada para verificar o paralelismo das curvas de crescimento, apresentou a sensibilidade necessária para detectar diferença entre os valores dos coeficientes $\mathrm{K}$ e $\mathrm{R}$, gerando um resultado consistente.

Dessa forma, para descrever o crescimento da altura dominante para as árvores dos novos grupos (Figura 2) foram utilizados os valores de $\mathrm{K}$ e $\mathrm{R}$ apresentados na Tabela 4, sendo que o coeficiente A da função de Richards foi reestimado, quando necessário, para corrigir o nível da curva de crescimento de um mesmo grupo ou para a altura desejada na idade índice (índice de sítio).

TABELA 4 : Valor dos coeficientes K e R da função de Richards utilizados para descrever o crescimento em altura dos Grupos A, B, C, D, E, F e G.

\begin{tabular}{l|c|c}
\hline \multirow{2}{*}{ Grupo } & \multicolumn{3}{c}{ Coeficientes } \\
\cline { 2 - 3 } & $\mathrm{K}$ & $\mathrm{R}$ \\
\hline $\mathrm{A}$ & 0,06889 & 1,57254 \\
$\mathrm{~B}$ & 0,05107 & 1,26179 \\
$\mathrm{C}$ & 0,09997 & 2,05820 \\
$\mathrm{D}$ & 0,07330 & 3,60090 \\
E & 0,08161 & 2,44677 \\
F & 0,02902 & 1,19503 \\
G & 0,07591 & 2,71293 \\
\hline
\end{tabular}



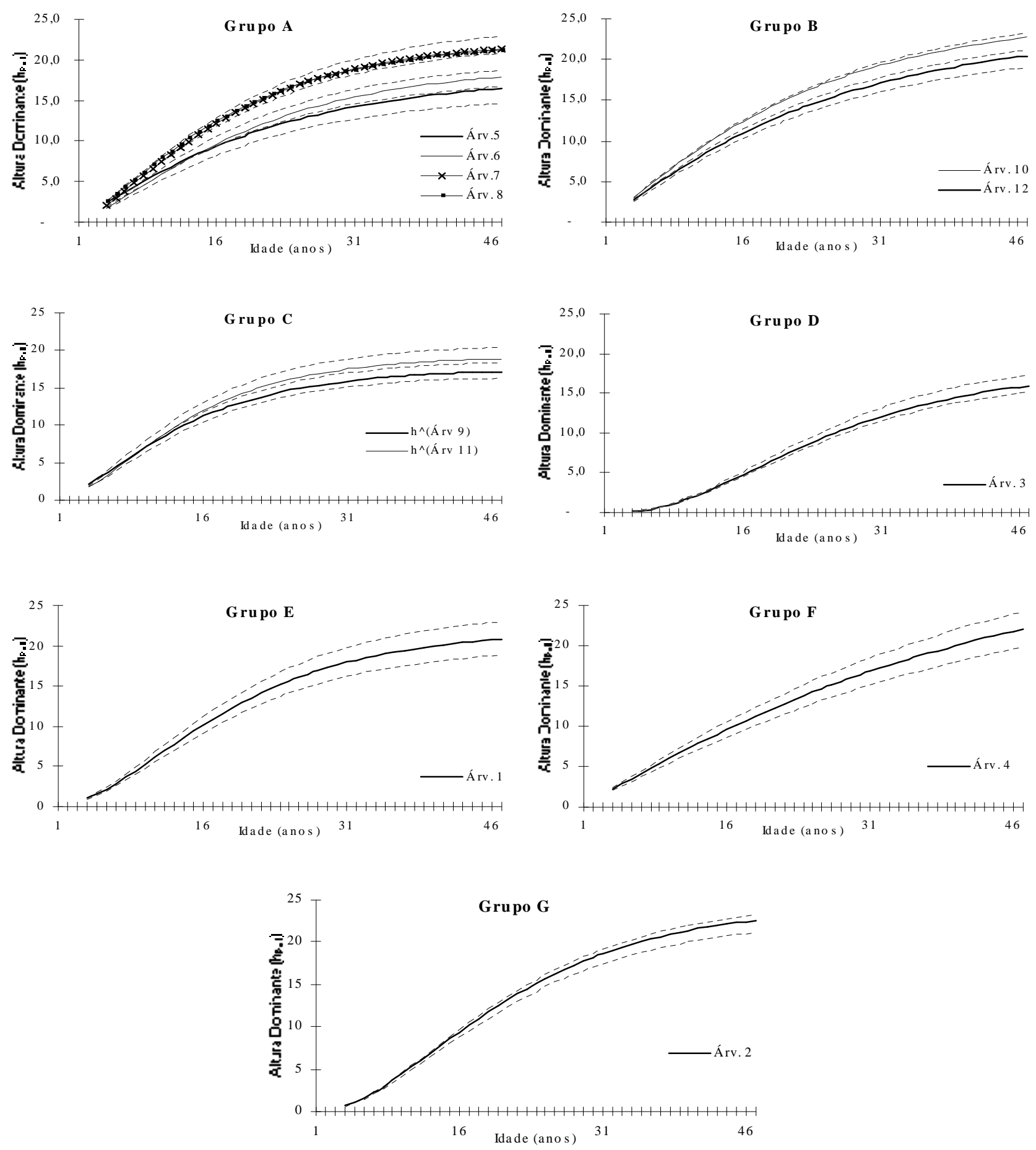

FIGURA 2: Grupos de árvores com semelhantes tendências de crescimento e índices de sítio. 


\section{CONCLUSÕES}

De acordo com os resultados obtidos neste estudo, pode-se concluir o seguinte:

a) A função de Richards de 3 coeficientes foi mais precisa para ajustar as curvas de altura em função da idade das 12 árvores de Araucaria angustifolia, com idades de 39 a 47 anos, pertencentes a diferentes sítios naturais, apresentando maiores valores de $\mathrm{R}^{2}$ e menores valores de $\mathrm{S}_{\mathrm{yx}}$;

b) A classificação de sítios naturais, realizada por IBAMA (1989), não é homogênea com relação à existência de uma única tendência de crescimento em altura dominante de Araucaria angustifolia (curvas monomórficas) para cada sítio, o que foi comprovado pela presença de árvores com diferentes tendências de crescimento em um mesmo sítio natural;

c) Foram encontradas sete tendências de crescimento em altura dominante nos três sítios naturais amostrados, indicando a necessidade de elaboração de sete sistemas de curvas índice.

\section{REFERÊNCIAS BIBLIOGRÁFICAS}

ALDER, D. Forest volume estimation and yield prediction. Roma: FAO, 1980. 80p.

BRASIL. Ministério da Agricultura. Levantamento e reconhecimento dos solos do Estado do Rio Grande do Sul. Recife, 1973. 431p. (Boletim Técnico, 30).

BURGER, D. Ordenamento florestal I. 2. ed . Curitiba: UFPR, 1976. v. não-paginado.

CARRARO, C. C., GAMERMANN, N., EICK, N. C. et al. Mapa geológico do Estado do Rio Grande do Sul. Porto Alegre: Instituto de Geociências, UFRGS, 1974. 29 p.

CASSOL, C. A. Relações entre características do solo, crescimento e produtividade em povoamento implantado de Araucaria angustifolia (Bert.) O. Ktze., em Passo Fundo - RS. Santa Maria: UFSM, 1982. 72 p. Dissertação (Mestrado em Agronomia) - Universidade Federal de Santa Maria, 1982.

DAVIS, K.P. American forest management. New York: Mc Graw Hill, 1954. 482 p.

FAO. El eucalipto en la repoblación forestal. Roma: FAO, 1981. 723 p.

FINGER, C. A. G. Ein Beitrag zur Ertragskunde von Eucalyptus grandis und Eucalyptus saligna in Suedbrasilien. Wien, Austria: Universitaet fuer Bodenkultur, 1991. 136 p. Tese (Doutorado) - Universitaet fuer Bodenkultur, 1991.

Fundamentos de biometria florestal. Santa Maria: UFSM, 1992. 269 p.

FISHWICK, R. W. Uso do percentual de espaçamento relativo de Hart-Becking para o controle dos desbastes. Brasilia: Prodepef - IBDF, 1975. 7 p.

GARCIA, V.D. Indice de sítio para Pinus insigne, en Chile. Santiago: Instituto Florestal, 1970. 138 p. (Inventário, 2).

GOLFARI, L. Coniferas aptas para repoblaciones forestales en el Estado de São Paulo. Silvicultura 
em São Paulo, São Paulo, v. 6, p. 7-62, 1967.

HEIBERG, S.O., WHITE, D.P. A site evaluation concept. Journal of Forestry, v. 54, n.1, p. 7-10. 1956.

HUECK, K. As florestas da América do Sul. São Paulo: Polígono, 1972. p. 206-239. 466 p.

IBAMA. Plano de manejo para a floresta nacional de Canela - RS. Santa Maria, 1989. 398 p.

IBDF. Zoneamento econômico florestal do Estado do Rio Grande do Sul. Curitiba, 1971. 125 p.

IPAGRO. Seção de Ecologia Agrícola. Atlas agroclimático do Estado do Rio Grande do Sul. Porto Alegre, 1989. 3 v.

MACHADO, S. A. Studies in growth and yield estimation for Pinus taeda L. - Plantations in the State of Paraná - Brasil. Washington: University of Washington, 1978. 170 p. (Tese Ph. D.) - University of Washington, 1978.

MOREnO, J. A. Clima do Rio Grande do Sul. Porto Alegre, Secretaria da Agricultura, 1961. 41p.

MOTA, F. S., BEIRSDORF, M. I. C., GARCEZ, J. R. B. Zoneamento agroclimático do Rio Grande do Sul e Santa Catarina: normais agroclimáticas. Pelotas: Instituto de Pesquisa Agropecuária do Sul, 1971. v.1

PEDRO BOM, R., BRENA, D. A. Modelos de crescimento e produção florestal. Curitiba: [s.n.], 1991. 111p.

RICHARDS, F. J. A flexible growth function for empirical use. J. Agr. Pres., v. 46, n. 7, p. 62-638, 1959.

RUSSEL, W. Site determination, classification and aplication. Journal of Forestry, v.15, n. 5 p. 552-553, 1971.

SCHNEIDER, P. R. ANATRO: programa de computador, ambiente MS-DOS. Santa Maria, 1984.

SCHNEIDER, P. R. Introdução ao manejo florestal. Santa Maria: UFSM， 1993. 348 p.

SCHNEIDER, P. R. Análise de regressão aplicada à Engenharia Florestal. Santa Maria: UFSM, CEPEF, 1998. 236p.

SELLE, G. L. Influência dos fatores ambientais na classificação de sítio para Pinus taeda L., na região de Cambará do Sul, RS, Brasil. Santa Maria: UFSM, 1993. 85 p. Dissertação (Mestrado em Engenharia Florestal) - Universidade Federal de Santa Maria, 1993.

SPURR, S.H. Forest inventory. New York: Ronald Press, 1952. 472 p.

VAN GOOR, C. P. Classificação da capacidade da terra em relação ao reflorestamento com Pinus elliottii Eng. var. elliottii e Araucaria angustifolia (Bert.) O. Ktze., no Estado de São Paulo. Silvicultura em São Paulo, v. 4, p. 349-366, 1965.

VAN LEAR, H., HOSNER, S. F. Correlation of site index and soil mapping units, poor for YellowPoplar in Southwest Virginia. Journal of Forestry, v. 65, n. 1, p. 22-24, 1967. 